\section{Reinforcement and reversibility in quantity conservation acquisition*}

\author{
CHARLES J. BRAINERD \\ University of Alberta, Edmonton 7, Alta., Canada
}

Two principal issues were addressed in this experiment: (1) the effectiveness of simple contingent reinforcement in the induction of conservation concepts in previously nonconserving children; $(2)$ the role of reversibility in conservation acquisition. Concerning (1), 20 nonconservers who were trained on liquid quantity conservation via contingent (verbal) reinforcement acquired a concept which was both superior to that of nontrained controls and statistically comparable to the naturally acquired concept. Concerning (2), the $20 \mathrm{Ss}$ who received contingent reinforcement also tended to acquire reversibility explanations. Finally, it was found that one of Piaget's two forms of reversibility (inversion) was more characteristic of the 20 reinforcement-trained conservers, while the other form of reversibility (reciprocity) was more characteristic of natural conservers.

Although many investigators have concerned themselves with the modus operandi of conservation acquisition during the past decade, two important questions remained unanswered: (1) Can simple contingent reinforcement induce conservation in previously nonconserving Ss? (2) Is either or both of Piaget's cognitive reversibilities associated with conservation acquisition?

The reinforcement question is interesting because contingent reinforcement of nonconserving judgments (i.e., informing a nonconserver that his judgments are "wrong") should, in theory, create the sort of "disequilibrium" which Piaget and his collaborators view as a necessary constituent of all cognitive acquisitions. At present, there are roughly equal amounts of evidence on either side. Both a group of nonsupportive experiments (e.g., Smedslund, 1961; Beilin, 1965) and a group of supportive experiments (e.g., Kingsley \& Hall, 1967; Gelman, 1969) have been reported. Since the reinforcement manipulations employed in these experiments typically have incorporated many extraneous factors which may be facilitating learning (in the case of the supportive experiments) and/or inhibiting learning (in the case of the nonsupportive experiments), it was decided to employ a rather simple form of reinforcement as the training treatment in this experiment. The simplicity of the treatment is defined by two major restrictions: (1) it did not emphasize any known form of conservation-relevant information (e.g., reversibility); (2) the Ss were

*This research was supported by U.S. Public Health Service Grant 19,226-01 to the author from the National Institute of Mental Health. provided with a small, manageable number of reinforcements. It was hoped that these two restrictions would produce a reasonably unequivocal answer to the question of whether or not reinforcement can induce conservation-without the massive time-consuming intervention reinforcement experiments such as Kingsley and Hall's and Gelman's.

The reversibility question is interesting because it embodies what is perhaps the major point of contention between Genevan and non-Genevan theories of conservation: while Piaget long has maintained that conservation results from the acquisition of inversion reversibility and reciprocity reversibility (cf. Brainerd \& Allen, 1971), both the Bruner group (e.g., Bruner, 1964) and Murray \& Johnson (1969) argue that reversibility is not a necessary component of conservation acquisition. Murray and Johnson have gone so far as to maintain that "reversibility is both logically and psychologically irrelevant to conservation [1969, p. 287]." The Bruner group and Murray and Johnson believe that their argument is supported by the well-established empirical fact that a certain proportion of children manifest reversibility in the absence of conservation. In this experiment, the reversibility question was addressed by determining whether or not previously nonconserving Ss tended to acquire reversibility explanations as a function of having their conservation judgments reinforced.

\section{SUBJECTS}

Fifty-two children ( 26 boys and 26 girls) from the first grade of a Western Ontario elementary school participated in this experiment. The Ss were chosen randomly without regard to any demographic characteristic programs reported in successful other than sex. The Ss' mean age was 6 years 3 months.

\section{APPARATUS}

The materials employed during the continuous quantity pretest, training, and posttest trials were: two identical medium-sized amber glasses, one tall-thin amber glass, and one short-wide amber glass (pretest and posttest trials); eight medium-sized blue glasses, two tall-thin blue glasses, and two short-wide blue glasses (training trials). The materials employed during the discontinuous quantity pre- and posttest trials were: two identical medium-sized colorless glasses, one tall-thin colorless glass and one short-wide colorless glass. The materials employed during the conservation extinction trials were six identical colorless glasses. Each of these latter glasses had a $2.5-\mathrm{cm}$ red stripe painted around its based to conceal the fact that two of the glasses had $2.0-\mathrm{cm}$-deep false bottoms. A beaker of colored water was employed during all continuous quantity trials and all extinction trials, while a beaker of dried peas was employed during all discontinuous quantity trials.

\section{PROCEDURE}

There were three basic steps-pretests, training, and posttests. The Ss were pretested for both conservation of continuous and discontinuous quantity via the standard Piagetian tests for these two concepts. In the continuous quantity pretest, $E$ began with two identical medium-sized glasses containing equal amounts of colored water and then poured the water from one of the identical glasses into a tall-thin glass. Next, E asked the following (randomly ordered) questions: (1) Do these two glasses contain the same amount of Kool-Aid? Why? (2) Does one of these two glasses contain more Kool-Aid? Why? (3) Does one of these two glasses contain less Kool-Aid? Why? This procedure then was repeated using a short-wide glass rather than a tall-thin one. The pretest for discontinuous quantity was the same, except that dried peas were used in place of colored water. In all, therefore, each S gave 12 "yes-no" pretest judgments and explained each judgment.

On the basis of the pretests, $12 \mathrm{Ss}$ were classified as "natural" conservers-i.e., these Ss gave consistently correct "yes-no" judgments on the 12 pretest questions. The remaining 40 Ss were clearly nonconservers: 35 of these Ss gave no correct pretest judgments; 3 of these Ss gave a single correct judgment; 2 of these Ss gave 2 correct judgments. The 12 natural conservers proceeded 
Table 1

Summary Statistics for the Five Posttest Variables

\begin{tabular}{|c|c|c|c|c|c|c|}
\hline \multirow[b]{3}{*}{ S Group } & & \multicolumn{5}{|c|}{ Dependent Variables } \\
\hline & & \multicolumn{3}{|c|}{ Judgments } & \multicolumn{2}{|c|}{ Explanations } \\
\hline & & $\begin{array}{l}\text { Contin- } \\
\text { uous }\end{array}$ & $\begin{array}{l}\text { Discon- } \\
\text { tinuous }\end{array}$ & $\begin{array}{c}\text { Extinc- } \\
\text { tion }\end{array}$ & $\begin{array}{l}\text { Contin- } \\
\text { uous }\end{array}$ & $\begin{array}{l}\text { Discon- } \\
\text { tinuous }\end{array}$ \\
\hline Control & $\begin{array}{l}\text { Mean } \\
\text { SD }\end{array}$ & $\begin{array}{l}0.20 \\
0.60\end{array}$ & $\begin{array}{l}0.20 \\
0.60\end{array}$ & $\begin{array}{l}0.25 \\
0.62\end{array}$ & $\begin{array}{l}0.20 \\
0.60\end{array}$ & $\begin{array}{l}0.20 \\
0.60\end{array}$ \\
\hline Reinforcement & $\begin{array}{l}\text { Mean } \\
\text { SD }\end{array}$ & $\begin{array}{l}5.00 \\
1.73\end{array}$ & $\begin{array}{l}5.00 \\
1.73\end{array}$ & $\begin{array}{l}2.85 \\
1.35\end{array}$ & $\begin{array}{l}4.25 \\
1.70\end{array}$ & $\begin{array}{l}3.90 \\
1.87\end{array}$ \\
\hline Natural Conserver & $\begin{array}{l}\text { Mean } \\
\text { SD }\end{array}$ & $\begin{array}{l}5.83 \\
0.38\end{array}$ & $\begin{array}{l}5.83 \\
0.38\end{array}$ & $\begin{array}{l}3.08 \\
1.19\end{array}$ & $\begin{array}{l}4.58 \\
1.80\end{array}$ & $\begin{array}{l}4.67 \\
2.21\end{array}$ \\
\hline
\end{tabular}

immediately to the posttests described below. Each of the 40 nonconservers was assigned randomly to one of two treatment conditions (reinforcement or control). The $20 \mathrm{Ss}$ in each condition received four repetitions of the continuous quantity pretest described above. In the reinforcement condition, a negative verbal reinforcement was made contingent on incorrect conservation judgments and a positive verbal reinforcement was made contingent on correct conservation judgments: as the continuous quantity pretests were repeated, E reinforced each "yes-no" judgment by saying either "you're right" (whenever $S$ made a correct judgment) or " you're wrong" (whenever $S$ made an incorrect judgment). The 20 reinforcement Ss received a total of 12 reinforcements each. The $E$ did not reinforce the training phase judgments of the 20 control Ss. It also should be noted that neither the reinforcement nor the control Ss were required to explain their 12 training phase judgments. That is, only conservation judgments and not conservation explanations were reinforced during training.

The posttests were of two sorts. First, the continuous and discontinuous quantity pretests were repeated verbatim. Second, the $S$ s were posttested for conservation extinction via a procedure devised by Brison (1966). The only departure from Brison's original procedure was that Ss were required to make the same six conservation judgments described above for the continuous and discontinuous quantity pretests rather than those described by Brison. Also, the Ss were not required to explain their judgments during the extinction posttest.

\section{RESPONSE SCORING}

For statistical purposes, all correct judgments (on both the pre- and posttests) were assigned " $1 \mathrm{s"}$ " and all incorrect judgments were assigned "0s." It was found that the explanations of these judgments could be grouped into five principal categories: (1) inversion reversibility (e.g., "You could always pour this one back here"'); (2) reciprocity reversibility (e.g., "This one is fat, but this one is skinny" or "This one is wider than this one"); (3) tautologies (e.g., "They're just the same" or “They're just different"'); (4) perceptual reasoning (e.g., "This one has more because it's tall"); and (5) "Don't know." The explanations were sorted into these categories with an interscorer agreement correlation (between two independent scorers) of .91 . For statistical purposes, explanations falling in the first two categories were deemed adequate and assigned "1s," while explanations falling in the latter three categories were deemed inadequate and assigned "0s."

\section{RESULTS AND DISCUSSION}

The analyses were of two sorts: (1) comparisons of the posttest performances of the 20 reinforcement Ss with both the posttest performances of the 20 controls and the 12 natural conservers; and (2) evaluation of the specific categories of explanations which the Ss in each of the three groups tended to employ to rationalize their conserving or nonconserving judgments.

The first group of analyses reveal whether or not simple contingent reinforcement-at least, as manipulated here-is capable of inducing conservation. In all, there were five dependent variables on which the posttest performances of the three $S$ groups could be compared: (1) continuous quantity judgments; (2) discontinuous quantity judgments; (3) extinction judgments; (4) continuous quantity explanations; (5) discontinuous quantity explanations. Mean and standard deviation values for each of these five posttest variables appear by $\mathbf{S}$ group in Table 1 . When the reinforcement and control groups were compared, all five comparisons attained significance and were in favor of the reinforcement $\mathrm{Ss}$ $\left(t_{s}=11.71,11.71,7.74,9.89,8.32\right.$, respectively; $\mathrm{df}=38 ; \mathrm{p}<.001$ in all instances). In constrast, when the reinforcement and natural conserver groups were compared, none of the five comparisons attained significance ( $\mathrm{ts}=-1.60,-1.60,-0.48,-0.51$, -0.99 , respectively; $\mathrm{df}=30 ; \mathrm{p}>.05$ in all instances). Each of these insignificant differences was in favor of the natural conservers. The magnitude of the first set of ts indicates that there was virtually no overlap between the posttest performances of the reinforcement and control Ss-the former were uniformly superior to the latter. Moreover, the fact that none of the five comparisons of the reinforcement Ss and the natural conservers deviated significantly from zero suggests that the reinforcement $S s$ acquired a concept that was at least statistically comparable to its naturally acquired counterpart. This latter conclusion also is supported by the following qualitative evidence: on the continuous and discontinuous quantity posttests, 15 of the 20 reinforcement $S s$ gave perfect strings of judgments (i.e., 12 correct judgments out of 12); the remaining 5 Ss gave 4 correct judgments each. All in all, then, contingent reinforcement appeared to work rather well.

The second group of comparisons reveal the extent to which reversibility is associated with conservation acquisition: if either or both of the two reversibilities is a necessary precondition for conservation (as Piaget maintains), then one would expect that the reinforcement $S$ should tend to shift their explanations-relative to the explanations of the controls-in the direction of some mention of reversibility. Mean and standard deviation values for the explanation data appear by $\mathbf{S}$ group in Table 2. Since only the first two explanation categories were of direct interest, the data for the latter three (inadequate) categories were collapsed into a single inclusive category. When the explanations of the reinforcement and control Ss were compared, the results were as anticipated: the reinforcement Ss gave significantly more inversion and reciprocity explanations than the controls $(\mathrm{ts}=5.89,2.56$, respectively; $\mathrm{df}=38 ; \mathrm{p}<.001$ and $\mathrm{p}<.01$ ), while the controls gave significantly more inadequate explanations $(t=8.27$; $\mathrm{df}=38 ; \mathrm{p}<.001)$. Whereas none of the 40 nonconservers gave any reversibility explanations on the pretests, two-thirds (i.e., 15) of the reinforcement $\mathrm{Ss}$ gave reversibility explanations on the posttests.

The results of the second group of comparisons are consistent with Piaget's position vis-à-vis reversibility and inconsistent with Bruner's and Murray and Johnson's contrasting 
contention that reversibility is irrelevant to conservation. Actually, this is not surprising. It seems that Bruner and Murray and Johnson have committed a reasoning error in the formulation of their argument: Piagetian theory postulates that both forms of reversibility are necessary preconditions for conservation. Logically, this amounts to a conditional assertion of the form, "If conservation, then reversibility." However, the data which both Bruner and Murray and Johnson believe disproves Piaget's thesis the well-known fact that some nonconservers possess reversibility) actually disproves the converse of Piaget's conditional thesis (i.e., "If reversibility, then conservation") rather than the conditional thesis itself. Since the converse of any conditional invariably is fallacious to begin with (cf. Wason, 1966), it is hardly surprising that the data cited by Bruner and by Murray and Johnson are inconsistent with it.

Finally, the explanations of the reinforcement and natural conserver groups were compared. The results indicated that the two groups did not differ in their numbers of inadequate explanations; however, the reinforcement $S s$ gave significantly more inversion explanations and significantly fewer reciprocity explanations than did the natural conservers $(\mathrm{ts}=1.51,2.96,-5.19$, respectively; $\quad \mathrm{d} f=30 ; \quad \mathrm{p}>.05$,

Table 2

Summary Statistics for the Explanation Data

\begin{tabular}{|c|c|c|c|c|}
\hline \multirow[b]{2}{*}{ S Group } & & \multicolumn{3}{|c|}{ Explanation Category } \\
\hline & & Inadequate & $\begin{array}{c}\text { Inversion } \\
\text { Reversibility }\end{array}$ & $\begin{array}{l}\text { Reciprocity } \\
\text { Reversibility }\end{array}$ \\
\hline Control & $\begin{array}{l}\text { Mean } \\
\text { SD }\end{array}$ & $\begin{array}{r}11.60 \\
1.20\end{array}$ & $\begin{array}{l}0.40 \\
1.20\end{array}$ & $\begin{array}{l}0.00 \\
0.00\end{array}$ \\
\hline Reinforcement & $\begin{array}{l}\text { Mean } \\
\text { SD }\end{array}$ & $\begin{array}{l}4.35 \\
3.69\end{array}$ & $\begin{array}{l}6.05 \\
4.07\end{array}$ & $\begin{array}{l}1.60 \\
2.76\end{array}$ \\
\hline Natural Conserver & $\begin{array}{l}\text { Mean } \\
\text { SD }\end{array}$ & $\begin{array}{l}2.50 \\
2.53\end{array}$ & $\begin{array}{l}2.17 \\
2.41\end{array}$ & $\begin{array}{l}7.17 \\
3.13\end{array}$ \\
\hline
\end{tabular}

$\mathrm{p}<.005, \mathrm{p}<.001)$. The latter two results are especially interesting because they cannot be predicted from Piagetian theory. Piaget treats both reversibilities as equally necessary for conservation acquisition, and therefore he establishes no specific developmental sequence between the two. However, the fact that the present trained conservers more frequently invoked inversion and less frequently invoked reciprocity than the natural conservers did suggests that one form of reversibility (inversion) may well be developmentally prior to the other (reciprocity).

\section{REFERENCES}

BEILIN, H. Learning and operational convergence in logical thought development. Journal of Experimental Child Psy chology, 1965, 2, 31 7-339.

BRAINERD, C. J., \& ALLEN, T. W. Experimental inductions of the conservation of "first-order" quantitative invariants. Psychological Bulletin. 1971. $75,128 \cdot 144$.

BRISON, D. W. Acceleration of conservation of substance. Journal of Genetic Psychology, 1966, 109, 311-322.

BRUNER. J. $S$. The course of cognitive growth. American Psychologist, 1964, 18 . 1-15.

GELMAN, R. Conservation acquisition: A problem of learning to attend to relevant attributes. Journal of Experimental Child Psy chology, 1969, 7, 167-187.

KINGSLEY, R. C., \& HALL, V. C. Training of conservation through the use of learning sets. Child Development, 1967, 38, 1111-1126.

MURRAY, F. B., \& JOHNSON, P. C. Reversibility in nonconservation of weight. Psychonomic Science, 1969, 16, 285-286.

SMEDSLUND, J. The acquisition of conservation of substance and weight in children. II. External reinforcement of conservation of weight and of the operations of addition and subtraction. Scandinavian Journal of Psychology, 1961, 2, 71-84.

WASON, P. C. Reasoning. In B. Foss (Ed.). New horizons in psychology. Harmondsworth, England: Penguin Books, 1966. 